\title{
DANIEL RIQUELME, O LAS GRIETAS ESCONDIDAS DE LA BRILLANTE HISTORIA NACIONAL*
}

\author{
DANIEL RIQUELME, OR THE HIDDEN CRACKS \\ OF THE SHINY NATIONAL HISTORY
}

\author{
Eduardo Aguayo Rodríguez \\ Universidad Católica de la Santísima Concepción. Concepción, Chile \\ eaguayo@ucsc.cl
}

\begin{abstract}
Resumen: Este artículo examina la prosa de divulgación histórica desarrollada por el escritor chileno Daniel Riquelme entre 1893 y 1911 en distintos medios periodísticos. Proponemos que el relato nacional delineado por este recuento histórico se aleja significativamente de la versión dominante de la Historia de Chile, asumiendo formas, actitudes y valores que la tensionan al punto de revertir su sentido. Para evaluar dicha hipótesis, nos interesa destacar la distancia que el relato de Riquelme logra establecer respecto de sus referentes literario-culturales -la historiografía y la novela nacionales- a partir del examen de sus procedimientos retóricos y de los efectos/afectos de lectura que caracterizan a esta prosa, sugiriendo una explicación que permita relacionar estas particularidades con el cambio en la percepción social del tiempo, desde un momento fundacional a uno de integración, y con el impacto social y cultural que la Guerra Civil de 1891 tuvo en este contexto.
\end{abstract}

Palabras clave: Daniel Riquelme, Historia de Chile, ficción histórica, héroe romántico, Revolución de 1891.

\begin{abstract}
This article examines the historical prose published by the Chilean writer Daniel Riquelme between 1893 and 1911 in different media. We propose that the national narrative delineated by this historical account departs significantly from the dominant version of Chilean History, assuming forms, attitudes and values that eventually stress and reverse its meaning. In order to evaluate the validity of this hypothesis, we study the distance that Riquelme's account establishes with respect to its literary-cultural references -national historiography and novel- examining its rhetorical procedures and the effects / affections of Reading that characterize this prose. Finally,
\end{abstract}

* Proyecto CONICYT/FONDECYT de postdoctorado No 3140170: 'Acá el sainete se convierte en tragedia’: la invención de Chile en la prosa histórica de Daniel Riquelme (18931911). 
we suggest an explanation to relate these textual particularities with the change in the social perception of the time, from a foundational moment to one of integration, and with the social and cultural impact that the Civil War of 1891 had in this context.

Keywords: Daniel Riquelme, history of Chile, historical fiction, romantic heroe, 1891 revolution.

Recibido: 05.03.2016. Aceptado: 30.11.2016.

\section{Introducción}

$\mathrm{E}_{\mathrm{t}}^{\mathrm{s}}$ STE ARTículo EXPONE los resultados obtenidos en el marco de una investigación que se propuso recuperar y examinar críticamente la prosa de divulgación histórica publicada por el escritor y periodista chileno Daniel Riquelme en distintos medios periódicos entre 1893 y 1911. Pretendimos con esto profundizar nuestro conocimiento sobre un autor poco estudiado, que produjo algunas páginas de mérito en el ámbito de la crónica, el artículo de costumbres y el relato breve, y que al final de sus días decidió distanciarse del ejercicio de la literatura para dedicarse a la popularización de la (o de una) "Historia de Chile".

A pesar de los escasos estudios críticos disponibles sobre esta etapa final en la producción del autor, algunas evidencias preliminares nos motivaron a plantear una hipótesis de lectura que justificara nuestra curiosidad por recuperar unos textos inactivos por más de un siglo: más que simplemente cumplir el encargo editorial de divulgar entre una emergente masa de lectores la versión dominante del relato histórico nacional -canonizado por la élite dominante del Chile decimonónico sobre todo a través del discurso histórico/historiográfico y literario/novelesco- los artículos y

${ }^{1}$ En un texto anterior describimos este corpus en detalle y expusimos en líneas generales el contexto de producción, circulación y consumo en el que se enmarca (Aguayo, 2014). Bástenos recordar acá que Riquelme presentó sus textos como una respuesta a "la amistosa exigencia de la Dirección de La Libertad Electoral, la que se empeñaba en vulgarizar el conocimiento de los sucesos notables de nuestra historia, en bien de los que, deseando instruirse en ellos, no tienen tiempo ni facilidades para leer grandes obras" (Riquelme, 1905: $\mathrm{s} / \mathrm{n})$. La decisión de la editorial de los hermanos Matte al parecer dio sus frutos, por cuanto Domingo Amunátegui Solar refiere que, a pesar de que el mérito literario de estos textos era considerablemente menor al de sus Chascarrillos militares, "el público leía con avidez cuanto artículo llevó la marca de su pluma” (Amunátegui, 1915: 226). 
relatos históricos de Riquelme elaboraron una visión más bien crítica de la memoria nacional, configurando una versión por momentos alternativa a la programada por los códigos culturales hegemónicos que centralizaron su funcionamiento social. Esta tensión estaría en sintonía, pensamos, con un cambio en la percepción colectiva del tiempo histórico, marcada por la crisis de sentido sufrida por el proyecto fundacional de la nación intensificada por la catástrofe histórica de 1891, y por la integración de sectores sociales emergentes a la matriz imaginaria de la nación (Subercaseaux, 2002).

Para comprobar los alcances y límites de la tesis expuesta, la investigación siguió dos líneas de estudio: la primera se propuso caracterizar la perspectiva narrativa desde la cual los textos de Riquelme enfocaron el relato de la historia nacional, con el objetivo de evidenciar tensiones o rupturas respecto del discurso historiográfico que le sirvió de fuente; la segunda se orientó a explorar el diálogo crítico y creativo que esta prosa estableció con algunos textos claves de la literatura nacional decimonónica, centrándonos especialmente en la resignificación del heroísmo épico-revolucionario propuesta en su novela La revolución del 20 de abril de 1851 (1893). En las líneas que siguen nos extenderemos en los aciertos y límites de esta lectura, examinando los procedimientos textuales que particularizan este corpus de estudio y lo distancian del modelo histórico-novelesco que le sirve de referencia y ofreciendo una explicación que ilumine el sentido de esta diferencia en el contexto histórico y cultural de su producción.

\section{Perspectivas de la historia}

Partamos señalando los límites de nuestra hipótesis. Si leemos los textos que componen nuestro corpus atendiendo a sus temas y contenidos, todo parece indicar que la prosa de Riquelme estaría lejos de proponer una versión alternativa a la consagrada por las fuentes historiográficas en las que se basa. Recordemos, en relación a esto, que la institucionalización de la historia en tanto disciplina socialmente productiva se inicia con la fundación de la Universidad de Chile y la puesta en marcha de su programa de investigación científico-literaria orientado por el modelo de Bello, cuyo plan metodológico privilegió la construcción de un conocimiento verificable sobre el pasado a partir de la exposición extensa y detallada de distintos 
registros documentales. El ideal de Bello se materializó en el trabajo de un grupo de literatos que canonizaron una tradición selectiva compuesta mayormente por la crónica política y militar de los hombres de la aristocracia local, los únicos elementos que resultaban memorables para una élite ilustrada, liberal en el plano económico y político, pero conservadora en el plano social y cultural ${ }^{2}$. Este impulso fundacional por historiar la nación no solo sentó las bases de lo que hoy conocemos por historiografía nacional, sino que constituyó uno de los principales referentes "literarios" del país durante gran parte del siglo XIX (Gazmuri, 2006; Subercaseaux, 2011).

Con esta tradición fundacional dialogó en principio la escritura de Riquelme, escenificando explícitamente su posición autorial con los gestos disciplinados, íntegros, del copista que transcribe al pie de la letra las palabras de un texto casi sagrado: "no se crea que apelo al romance -aclara en Historia de dos crímenes. Muerte de Portales- al hacer esta relación, que sólo me cuesta el trabajo de haberme leído cuanto se ha escrito acerca de esos lejanos sucesos" (Riquelme, 1932 [1894]: 90). En efecto, Riquelme insistió a lo largo de los años en presentar estos textos como simples apuntes que cumplirían el humilde pero noble propósito de popularizar entre las emergentes masas lectoras "la religión de los grandes recuerdos nacionales" (1888, septiembre 17), basándose en la conmemoración de los hitos que, gracias a las memorias anuales pronunciadas en la academia de Bello, eran ya reconocidos por la elite letrada como "los hechos más señalados de la historia de Chile" (Gazmuri, 2006: 61): la Guerra de la Independencia de Chile, en especial las batallas de Rancagua, Chacabuco y Maipo; los sucesos relacionados con la instauración de la primera junta de Gobierno; la conformación de la Primera Escuadra Nacional y sus efectos en la Guerra de Independencia; el ascenso, apogeo y caída de O'Higgins; el descubrimiento y conquista de Chile, sobre todo a partir de la figura protagónica de Pedro de Valdivia, entre otros episodios. Sólo añadamos, para cerrar este punto, que la subordinación de Riquelme a esta tradición histórica se extremó al

\footnotetext{
${ }^{2}$ Por tradición selectiva entenderemos "aquello que, dentro de los términos de una cultura dominante efectiva, siempre se hace pasar como 'la tradición', 'el pasado significante"” (Williams, 2005: 39). Recurriremos en lo sucesivo a la conceptualización desarrollada por Raymond Williams en relación a las expresiones culturales dominantes y emergentes como un referente teórico importante, a pesar de que en estricto rigor nuestra lectura no corresponda a un análisis "culturalista” de la obra de Riquelme.
} 
punto de que gran parte de lo que leemos en sus textos corresponde a citas extensas y literales extraídas de una biblioteca que mezcla obras "clásicas" de la historia decimonónica, matizada con la lectura de autores contemporáneos y de gusto más masivo ${ }^{3}$.

Considerando estos antecedentes, la posibilidad de reconocer en la historia de Riquelme una lectura alternativa del pasado nacional parece improbable; sin embargo, un análisis atento al modo en que se construyen los episodios seleccionados para articular su historia de Chile revela las significativas diferencias que distancian su relato histórico de la versión dominante, como cabría esperar de un proyecto cuyo objetivo declarado es, precisamente, vulgarizar el relato nacional, hacerlo popular. ¿Qué significó esto en el caso de Riquelme? Seguir el camino que dejaron las huellas formales de esta reescritura conducirá a develar el sentido crítico que, pensamos, subyace a su proyecto de popularizar la historia oficial de la nación; sin embargo, dejemos anotada antes una idea de orden general: a diferencia de la historiografía "académica", condicionada hasta cierto punto por las normas y convenciones que regulan su producción en el ámbito de una comunidad de conocimiento específica, la escritura de divulgación histórica, como género o modo específico de hacer memoria ${ }^{4}$, opera actualizando los episodios del pasado de manera menos objetiva o tal vez más sensible a las variaciones y necesidades que plantea la contingencia, en la medida en que "escucha los sentidos comunes del presente, atiende las creencias de su público y se orienta en función de ellas" (Sarlo, 2013: 15). En este

${ }^{3}$ Entre los textos históricos más utilizados por Riquelme, destacamos: de Vicuña Mackenna, Historia de los diez años de la administración de don Manuel Montt. Revolución del Sur (1862); Introducción a la Historia de los diez años de la administración Montt: Don Diego Portales (1863); Historia crítica i social de la ciudad de Santiago (1869), e Historia de la jornada del 20 de abril de 1851 (1878); de Miguel Luis Amunátegui, El terremoto del 13 de mayo de 1647 (1882); de Diego Barros Arana, Historia General de Chile, especialmente los tomos VIII (1887) y XI (1891); además de estas fuentes, Riquelme recurre marginalmente a textos claves del memorialismo para ampliar sus anotaciones, entre los cuales destacamos Recuerdos de treinta años (1872), de José Zapiola, y Recuerdos del pasado (1882) de Vicente Pérez Rosales.

${ }^{4}$ Sobre este punto, Astrid Erll (2008) propone que, dado que el pasado no es un contenido "dado", sino que debe ser continuamente re-construido y re-presentado, la memoria individual y colectiva sobre este pasado variará en función de qué es lo que recuerda, pero también de cómo esto se lleva a cabo. De ahí que la autora considere a la historia, el mito, la religión o el sicoanálisis como formas distintivas de hacer memoria, antes que como discursos en oposición a ésta. 
sentido, la historia para las masas es un relato que se presenta a sí mismo como políticamente activo, en continuo diálogo con las fuerzas del presente, develando sus fracturas, respondiendo a sus transformaciones. Quien la escribe no trabaja animado por la pretensión, propia del historiador profesional, de establecer o restituir una posible verdad objetiva sobre el pasado, aunque a veces insista en declarar lo contrario; más bien, aprovechando las formas y los contenidos del discurso histórico - digamos, sus condiciones de verosimilitud y veracidad- este conmemorador adapta el pasado a las necesidades e intereses del presente, proponiéndonos "ídolos para venerar y enemigos para aborrecer" (Todorov, 2002: 159). ¿Quiénes son los enemigos y los ídolos de mi público? ¿Cómo despierto sus simpatías y odios? son preguntas que guían y que finalmente validan socialmente este tipo de textos, y sobre ellas deberíamos enfocar nuestro análisis si queremos entender el sentido de esta clase de discurso ${ }^{5}$.

Pero regresemos a Riquelme. Popularizar la historia de Chile significó, para el autor, volver a contarla en un modo y con un sentido congruentes con las características de su público objetivo, una masa amplia y heterogénea de lectores y lectoras que no disponían de mayores recursos materiales e intelectuales ${ }^{6}$. Decimos "contarla" antes que "escribirla", por cuanto el acto se ajusta mejor a la perspectiva narrativa que organiza el relato en la mayoría de sus artículos históricos. Examinemos el siguiente fragmento a modo de ejemplo:

Yo no alcancé a ver, y me alegro por mí, lo que en su tiempo fue esa bullada ceremonia, nos decía el viejo don Santos en la visita que le hicimos algunos amigos el viernes último, 12 de febrero; pero es lo mismo, agre-

\footnotetext{
${ }^{5}$ Tal vez una de las diferencias más significativas entre la "historia profesional" y el relato del conmemorador sea la especial conciencia -y de ahí, el dominio- que este último tiene sobre la artificialidad de su material narrado: "la historia es líquida", afirma Jorge Baradit en el prólogo de su Historia secreta de Chile, el ejemplo más actual de este género narrativo en Chile, "es blanda, moldeable, cortable, redefinible y esculpible. No está hecha de mármol: es arcilla en manos de vencedores y de la clase dominante" (2015: 5).

${ }^{6}$ Una caracterización orientadora de la composición y evolución de los sectores medios y populares en el Chile decimonónico puede encontrarse en Salazar y Pinto (1999); para un detallado análisis de la relación entre la prensa periódica y la integración de estos grupos sociales en los procesos de formación lectora durante el mismo periodo, consúltese Ossandón y Santa Cruz (2001), y Poblete (2003).
} 
gaba, que si la hubiera presenciado cien veces; porque mi padre, que fue de los que se arrodillaron en la Plaza de Armas sombrero en mano, como si pasara el Santísimo, para jurar que con su sangre sostendrían la Independencia, la recordaba siempre que venía al caso.

El se la contaba a los suyos y yo, a mi vez, se la repito a los míos, y así se forma la tradición: de oreja en oreja (Riquelme, 1909, febrero 16).

La cita, extraída de Recuerdos de un viejo. La jura de la Independencia, nos parece destacable en varios sentidos. En primer lugar, la presencia de un personaje-narrador, que acompaña y por momentos desplaza la voz autoral -un nosotros apenas esbozado- y que al mismo tiempo se encarga de vocalizar el testimonio de otro -su padre- , abisma la narración histórica en un encuadre claramente ficcional que "auraliza" el acto de lectura a través de una serie de verbos vinculados a situaciones orales de comunicación: decir, recordar, contar, repetir “de oreja en oreja”. El recurso, aunque limitado, reaparece en otras ocasiones -un veterano de Loncomilla en "Entre Loncomilla i Tacna" (1893), un "viejo amigo, que me sirve como diccionario de cosas chilenas" (1931 [1909]: 483) en La revolución de los sastres de Valparaíso- y es el artificio fundamental para novelar la historia en La revolución del 20 de abril de 1851 (1893), como veremos luego. La opción por oralizar la escritura, por acercarla al registro propio de la conversación, repercute en la representación del contenido histórico, que se subjetiviza en la ficción para transformarse en un testimonio vicario -es decir, en recuerdo de un recuerdo-, estableciendo una primera distancia, formal y epistemológica, con respecto al discurso histórico tradicional, siempre alerta a los peligros que planteaban, al decir de Vicuña Mackenna, "los inciertos archivos de la memoria [y] la tradición oral" (1862: 14). De esta forma, al igual que ocurre con sus famosos "chascarrillos militares" de 1885, el valor de la historia, para Riquelme, parece residir más bien en su narratividad que en su veracidad: la historia que vale es la que puede contarse y, por lo tanto, recordarse.

Lo anterior se relaciona con el valor que adquieren en sus textos los "detalles caseros y pintorescos" (Riquelme, 1909, agosto) de la historia, transformando el recuento sistemático de los hechos en una especie de "almanaque de la patria" (Riquelme, 1910, enero 23), lo que significó incluir, en ocasiones, detalles de dudosa validez histórica. Sucede, por ejemplo, cuando se aparta del registro de Vicuña Mackenna para contar el destino 
del carro que transportó a Portales hacia su muerte, convertido luego, según afirma Riquelme, en un amansador de caballos, historia intercalada que funciona como pretexto para mencionar una supuesta inscripción garabateada en el vehículo:

se descubrió que el maestro herrero de la hacienda, al transformarlo en amansadora, le había gravado esta leyenda, eco lejano, pero no perdido de la voz de ese pueblo que solo conoció del gran Ministro sus grandes disciplinazos: Este amansó a Portales! (1932 [1894]: 85).

Significativamente, es a través de estos detalles que la "voz del pueblo" irrumpe entre los pliegues de la historia oficial. Detalles modulados con los usos coloquiales del habla popular, con sus comparaciones, sus metáforas y sus dichos, integrados para explicar y describir personajes, eventos y procesos históricos y al mismo tiempo para generar un notorio efecto de cercanía. Transcribamos algunos ejemplos: para describir al gobernador López de Ulloa, que según Riquelme "murió de melancolía" al no poder aliviarse del pesar causado por una serie de desastres naturales que golpearon Santiago, se dice que era "simpático i tímido como una laucha" (1894, mayo 31); refiriéndose al benévolo gobierno de Ambrosio de Benavides, señala que "había sido como una cataplasma de miga de pan con leche" sobre la piel sufriente del Santiago colonial (1898, junio 23); sobre la deportación de dos espías franceses descubiertos conspirando a favor de la independencia de Chile, agrega que fueron expulsados del país "con todas las ceremonias prescritas para que los gatos pierdan el camino de la querencia cuando los trasladan de una casa a otra" (1898, junio 23); al resumir los cambios que el gobierno de Muñoz de Guzmán trajo a la vida social santiaguina, explica que fue "una transformación tan radical en las costumbres como la de dejar el mate por el té y la novena o el rosario por el teatro" (1898, abril 14); del gobernador español Mariano Osorio se afirma que, cegado por la soberbia, creía que en Chile "los laureles se cortaban como escobas" (1899, abril 5); para ilustrar la falta de dinamismo de la sociedad colonial, señala que sus días eran "siempre iguales, como dos bostezos seguidos" (1909, diciembre 20); en fin, al describir una balacera entre amotinados y fuerzas regulares durante uno de los tantos conflictos civiles de 1851, Riquelme cede la palabra a un soldado raso, que ordenaba a sus camaradas: "iApúntenle a ese rucio cabezón! iAl cabeza de zapallo!” (1931 [1909]: 503). 
La irrupción continua de estas voces populares agrega, como vemos, una dimensión humorística a su prosa, rasgo que establece otra distancia más entre la historia de Riquelme y el solemne registro histórico construido por los literatos decimonónicos, afectados en su mayoría de gravedad incurable 7 . Es muy importante notar, sin embargo, que el humor con que Riquelme narra la historia de Chile transita siempre desde lo simplemente cómico a lo amargamente irónico. Sobre este punto, recordemos, siguiendo a Hayden White, que la comedia, en tanto que trama histórico-narrativa, propone la reconciliación de los conflictos sociales que movilizan el devenir histórico bajo la ilusión de una armonía final entre fuerzas en principio irreconciliables; la ironía, por contraste, nos revela el eterno desgarramiento que termina por anular toda posibilidad de concordia. Sugerentemente, esta conciencia irónica del pasado se activa en varios textos de Riquelme para apelar a su propio presente histórico, enfatizando el enfrentamiento al parecer sin solución entre las élites gobernantes y las capas populares. Esto se hace particularmente evidente al recordar las movilizaciones políticas y militares de 1851, dirigidas por las élites liberales en contra del régimen autoritario-conservador que detentaba el poder tras la derrota de los liberales o "pipiolos" en Lircay en 1830, y que Riquelme describe como una lucha en pos de "los derechos políticos del pueblo, cuya masa, como hoi día, no sabía leer ni escribir, aun cuando tantas veces la hayan hecho escribir con su sangre lo que no entiende" (Riquelme, 1898, diciembre 14). Esta contradicción social, para el autor, constituye una línea fundacional e ininterrumpida de la historia nacional, que puede verificarse desde la misma gesta de la Independencia, como demuestra "el oro prodigado en los uniformes de los jóvenes oficiales [y] los tristes harapos que apenas cubrían la tropa" (1894, mayo 4).

Subercaseaux (2011) ha llamado la atención sobre la solemnidad con que los miembros de la Sociedad Literaria de 1842 conducían sus reuniones. El crítico interpreta la estricta normatividad que organizaba estas tertulias, y que no dejaba espacio para la emotividad, el irracionalismo o el humor, como una evidencia de la conciencia histórica fundacional con la que esta generación afrontaba la tarea intelectual en la post-independencia. Esta conclusión puede ser ampliada por una observación de carácter sociocultural aportada por Salinas (1998), cuando señala que en el contexto chileno la cultura del humor se halla fuertemente vinculada al desarrollo de una comicidad popular heredera de elementos culturales residuales de raíz hispano-indígena, mismos referentes que durante el siglo XIX fueron mayormente interpretados por las elites fundadoras como factores de involución histórica. 
La evidencia expuesta hasta el momento nos permite afirmar, en síntesis, que la prosa histórica de Riquelme, si bien dista de inventar una nueva versión de los relatos establecidos por la historia tradicional de Chile, sí plantea una lectura de esta historia que no resulta neutra sino que, al contrario, tiende a desmontar el modo dominante de contar la historia nacional que le sirve de base, configurando una perspectiva narrativa alternativa, basada en la asimilación de las formas orales en la escritura, la subjetivación del registro histórico, la inclusión del humor popular y la ironía para explicar el sentido de los hechos narrados y el establecimiento de una cierta distancia crítica respecto de la relación entre las clases dominantes y los sujetos populares. Estos rasgos, que pueden ser detectados de forma dispersa a lo largo del corpus en estudio, se condensan particularmente en su novela La revolución del 20 de abril de 1851 (1893), texto a partir del cual abordaremos nuestra segunda línea de investigación: la (re)significación que la prosa de Riquelme propone de un cierto heroísmo civil cultivado tradicionalmente por los romances históricos y nacionales.

\section{Heroísmo y cobardía en el romance nacional: La revolución del 20 de abril}

Publicada por entregas en el diario La Libertad Electoral entre el 27 de abril y el 11 de mayo de 1893, La revolución del 20 de abril es el intento literario más ambicioso de Riquelme, por lo menos en lo que se refiere a su proyecto de divulgación histórica ${ }^{8}$. La novela recupera algunos episodios del fallido levantamiento cívico-militar organizado por la Sociedad de la Igualdad contra el gobierno conservador del general Bulnes, basándose fundamentalmente en los capítulos XXII al XXIX de Historia de la Jornada del 20 de abril de 1851 (1878), testimonio histórico de uno de los promotores más activos del motín: Benjamín Vicuña Mackenna. La primera versión de la novela fue refundida y publicada por la imprenta del mismo

\footnotetext{
${ }^{8}$ La producción literaria de Riquelme incluiría entre otros logros, además de sus ya clásicos Chascarrillos militares (1885), una serie de relatos de influencia modernista, entre los que destacan "X..." (1887), "Un poseur" (1888), "El loco del espediente" (1888) y "Era un Sueño (1889)”, todos publicados en las páginas del diario La Libertad Electoral.
} 
periódico a fines de 1893, y sirvió de guía para una segunda edición, compilada por Latorre y Varas a partir de un ejemplar corregido por Riquelme ${ }^{9}$. De esta edición derivó la versión publicada por Editorial Andrés Bello en 1966 bajo la dirección de Raúl Silva Castro, que incluyó algunas modificaciones menores, relacionadas en su mayor parte con la modernización de la ortografía ${ }^{10}$.

Tal como ocurre con la mayoría de los textos comprendidos en nuestro estudio, Riquelme basó el contenido de su relato extensa y casi literalmente en el registro historiográfico, aunque el artificio narrativo propuesto para "novelar" este sustrato histórico resulta mucho más elaborado en comparación con sus otros artículos. La novela cuenta la historia de Francisco Sandoval, un modesto comerciante retirado y antiguo miembro de la Sociedad de la Igualdad, que recuerda su participación en el motín del 20 de abril ante la atenta escucha de su nieta Beatriz y de un joven periodista, quien creció oyendo sus historias y que lo trata cariñosamente de "don Panchito". La tertulia se desarrolla en una pequeña sala de lectura, íntima y confortable, un lieu de mémoire alumbrado "dulcemente por la lámpara de las charlas patriarcales, la lámpara de aceite" (Riquelme, 1893: 5) y por el fuego colonial de un brasero, mientras comparten un "viejo asoleado de Cauquenes [con] sus torrejas de naranja agria" (6). Sabemos de estos detalles gracias al periodista, narrador principal y "autor" del texto, que a su vez está recordando -fielmente, "punto por punto" (185)- lo referido esa noche ya lejana, como homenaje a la memoria de Sandoval. Una lectura atenta revela, sin embargo, que los recuerdos de "don Panchito" son en gran medida apuntes resumidos del texto de Vicuña Mackenna, disfrazados bajo la forma convencional del romance.

${ }_{9}$ En una nota introductoria a esta versión, Manuel Varas detalla: "Las diferencias que se notan entre este trabajo y el folleto de Daniel Riquelme corresponden a las modificaciones que él mismo introdujo a su primer libro y que constan del ejemplar corregido de su puño y letra y obsequiado a don Samuel Ossa Borne, del cual lo tomamos. Es un ejemplar preparado para hacer una segunda edición, razón por la cual lo hemos preferido al ya conocido" (Latorre y Varas, 1931: 389). Agreguemos que las diferencias entre las distintas versiones del texto publicadas en formato de libro son importantes, pero más significativas resultan las que distinguen la primera versión del texto de las versiones posteriores; en este ámbito, destacamos el final original de la novela, eliminado en las sucesivas ediciones.

${ }^{10}$ Curiosamente, esta última versión fue incluida por Seymour Menton en la lista de la "no-tan-nueva" novela histórica latinoamericana, junto a autores más bien contemporáneos como Luis Enrique Délano o Manuel Mujica Laínez (Menton, 1993: 16). 
Es válido suponer que, al proponerse narrar la historia del 20 de abril "como si fuera novela" (13), Riquelme haya tenido a Martín Rivas (1862) como modelo, sobre todo si consideramos la explícita referencia que Vicuña Mackenna hace del romance de Blest Gana al final de su testimonio histórico:

Sabido es que en la interesante novela de A. Blest Gana, titulada «Martín Rivas» se describen con lucida fantasía algunos de los cuadros del 20 de abril, mezclando el amor con la guerra, el miedo con la baratería i el logrerismo político. Los que quieran por tanto conocer a los barateros de aquel tiempo, como tipos morales i patrióticos, averigüen en esa novela, quién era el señor don Dámaso Encinas, futuro suegro de «Martín Rivas» i Amador Molina. Los tipos de Rafael San Luis, que tantos se han apropiado, no brillaron ese día, particularmente alrededor de la Moneda... (1878: 642. Cursivas en el original).

La cita de Vicuña Mackenna, que parece ofrecer a Riquelme un esquema narrativo sobre el cual basar su texto - una historia patriótica de amor y de guerra que narra el derrotero político de una generación que se apagaresulta significativa en la medida en que apunta a un tema sin duda problemático para la historia nacional que desea narrar nuestro autor: la figura del héroe y su significación colectiva. Valgan en este punto algunas consideraciones. En el contexto histórico y cultural que comparten Blest Gana, Vicuña Mackenna y, parcialmente, Riquelme, los sentidos y las formas de lo heroico tendieron a configurarse colectivamente a partir del modelo dominante que instauró la figura del héroe burgués moderno, de matriz militar, nacionalista, revolucionaria y romántica (Vovelle, 2003; Mínguez, 2003). Al igual que el héroe clásico, el héroe civil que Vicuña Mackenna añora encontrar en las calles de Santiago se define por una valentía monolítica, que se expresa en su disposición a enfrentar la muerte violenta -la propia y la del otro- sin dejar espacio para la duda; a diferencia del modelo clásico, sin embargo, el sentido del heroísmo que el intelectual busca pero no encuentra entre sus pares está fijado por un horizonte histórico-social -la Revolución francesa, con su ideal igualitario y libertario- y por un horizonte estético-ideológico, el romanticismo, que ve en la muerte heroica el mayor acto de autenticidad, la "afirmación de la propia vida y negación de la vida impuesta” (Falleto y Kirkwood, 1976: 150). 
Si bien a primera vista podría resultarnos extraño que un historiador como Vicuña Mackenna convocase a un personaje de ficción -Rafael San Luis, héroe romántico por excelencia- para ejemplificar el heroísmo que no pudo encontrar entre las filas liberales durante la jornada de abril, podemos entender esta filiación si atendemos al origen de la fascinación heroica que anima el trabajo del historiador: la lectura de La historia de los girondinos (1847) de Lamartine, libro que en gran medida sirvió de modelo, inspiración e incluso guía espiritual para los esfuerzos revolucionarios de su generación. En este sentido, resulta interesante recuperar la propuesta de Manuel Vicuña cuando afirma que el actuar de Vicuña Mackenna y de parte de sus camaradas está mediatizado por un intenso bovarismo que se evidencia, por ejemplo, en el gesto de adoptar como suyos los nombres de los revolucionarios franceses en vísperas del levantamiento santiaguino, a la manera de un canibalismo simbólico que les permitiera "apropiarse de una fuerza volitiva [para] convertirse en otro sujeto más sublime: un héroe" (Vicuña, 2009: 171). Ese canibalismo opera disolviendo la frontera que separa ficción de realidad; de ahí que al historiador le bastara el sacrificio heroico de Rafael San Luis para habilitarlo como un modelo con el que comprender y operar sobre el mundo, sobre todo si por medio de ese sacrificio se aseguraba, aunque solo fuese imaginariamente, la "investidura heroica" de la burguesía liberal puesta en entredicho por los eventos históricos de la jornada del 20 de abril (Concha, 2012: 35). Precisamente, gracias a que Vicuña Mackenna ha arriesgado su vida del mismo modo en que lo ha hecho el personaje literario, siguiendo el modelo heroico, revolucionario y romántico de sus lecturas, es que se otorga el privilegio de juzgar lo que considera una actitud conformista y acomodaticia de parte de las elites liberales, o, para citar sus propias palabras, la "ignominia de la poltronería i del menguado egoísmo que todo lo [pospuso] al amor barato de la vida" (1878: 533).

Sabemos, por otra parte, que el componente erótico-sentimental que el romance agrega a este heroísmo marcial y revolucionario se expresó durante el siglo XIX en una cierta masculinidad imaginada a partir de una potencia central: la valentía inflexible del héroe. Recordemos que luchar por la patria para conquistar, por este medio, el corazón de la amada constituye un tópico recurrente de la novela histórica decimonónica (Unzueta, 
1997), actualizado en cada texto que buscó enlazar, en el plano imaginario, el heterogéneo tejido social de las jóvenes repúblicas latinoamericanas a través de "fantasías eróticas y políticas" (Sommer, 2004: 66) capaces de fundar una familia nacional. En este contexto, no optar por el heroísmo constituye una doble traición, a la patria y al género, ya que no puede existir maridaje entre los distintos estamentos nacionales, no puede existir enlace productivo sobre el cual construir una nacionalidad, si antes el hombre no prueba su hombría en la lucha. Se entienden así las palabras con las que Martín Rivas se decide por el bando revolucionario: "En vez de llorar desengañados como mujeres, podemos consagrarnos a una causa digna de hombres" (Blest Gana, 2013: 447). Algo similar sucede en el caso de Los secretos del pueblo (1870) de Martín Palma, cuyo protagonista, Enrique López, joven artesano y miembro también de la Sociedad de la Igualdad, ha abrazado la revolución movilizado por el doble deseo, político-erótico, de luchar contra la tiranía conservadora y obtener, por medio de su compromiso heroico, el reconocimiento de Luisa, la mujer que ama. La inexperiencia guerrera del joven obrero contrasta con la de su padre, veterano de las guerras de Independencia, quien al principio expresa temor por la suerte que puede correr su hijo en la batalla, pero que luego corrige su debilidad inicial alentando al joven Enrique a luchar con estas palabras: "Cuando es llegado el momento el hombre debe ser hombre. Delante del peligro no se llora sino que se chorea (35)". Esta suerte de compromiso de género es, en efecto, la reafirmación de una lógica espacial que asigna un lugar -público v/s privado- a los cuerpos sexuados: “¿Acaso los hombres se han hecho únicamente para estar en la casa? (26).

$\mathrm{Al}$ igual que ocurre con estas figuras heroicas -que, a pesar de situarse políticamente desde un lugar de oposición, a nuestro juicio participan de un modelo central o hegemónico de civilidad y de masculinidad- la aventura política en la novela de Riquelme se enlaza también con la conquista erótica de Ema, la mujer a la que aspira el joven Sandoval: "Muerto por la Patria o sin mancha para ti!" (1893: 19) exclama Francisco, antes de marchar al incierto motín con el resto de los conjurados, adoptando en este punto los gestos dramáticos adecuados a la situación heroica. Este último detalle no deja de ser significativo, si consideramos que el héroe se escribe socialmente, también, a través de una gestualidad monumental, una suerte de postura con la cual se actúa en los momentos decisivos. Es la pose 
que describe Francisco Bilbao, desde la vereda de la historia, al recordar su participación en el levantamiento liberal peruano de 1854, liderado por el general Ramón Castilla contra José Rufino Echenique: "Encontramos una masa de pueblo, y entonces hablé, rifle en mano, unas pocas palabras, que hace nos dirijamos todos a carrera a la plaza. [...] Entonces empezó el desorden incontenible. Saquearon la casa de Echeñique. Yo estaba muy contento" (1864, citado en García, 2011: 161. Cursivas en el original). Enfrentado a otro momento culminante de la historia, Blest Gana coloca en una postura similar al héroe de su romance: "Adelante, muchachos! -gritó Martín, blandiendo la espada en una mano y en la otra una pistola” (483); coincidentemente, el mismo gesto reaparece en la novela de Riquelme, salvo que esta vez la escena se enfoca desde una perspectiva que nos resulta novedosa. Relata Sandoval:

Recuerdo, como si lo estuviera viendo, a un joven que llegó armado con una escopeta, una figura de las barricadas de Lamartine. A su vez tomó la palabra, diciendo que iba a derramar su sangre por la libertad i los santos derechos del pueblo oprimido.

¡De vosotros! -concluyó el joven, estendiendo los brazos hacia la turba. ¿Qué negocio irá a hacer este futre? -gritó un roto (1893: 38).

El uso irónico que Riquelme hace de esta verdadera escena matricial escenifica una vez más la irreconciliable distancia que separa al "pueblo" de sus autonombrados mesías -los "futres" de siempre- en su prosa histórica, a la vez que contagia este relato particular con un escepticismo que contrarresta, hasta cierto punto, el potencial mimético del heroísmo revolucionario. A partir de este momento, el curso de la narración instalará al protagonista en una posición alternativa que concluirá por "rescatarlo" del influjo bovárico del héroe, enfrentándolo a un escenario vital que ni Martín Rivas ni Vicuña Mackenna pudieron o quisieron reconocer. Trascribimos el fragmento en extenso:

Sin embargo -ii que esto me salve!- miré con algún horror el escopetón que había sacado del Cuartel de Bombas; volví a ver en esa misma Cañada a los artilleros [enemigos]: rotos sumisos que entonces, como ahora, cumplían el mismo deber. Se me representaron, sobre todo, las caras venerables de esos viejos sarjentos, encanecidos en el servicio [...] I yo iba a disparar sobre esos veteranos, que, antes que yo naciera, ya 
combatían por la Independencia, casados con otra viejecita, llenos de chiquillos, con hijas como Ema, con nietos como mi Beatriz!...

Callado la boca, le pasé el escopetón a un roto... (1893: 93, 94).

A diferencia de Rivas y San Luis, que despreciaron, para consuelo de Vicuña Mackenna, el vergonzoso y barato amor a la vida y prefirieron rivalizar "en arrojo y valentía” (Blest Gana, 2013: 484), olvidando que "cada tiro regaba el suelo chileno con la generosa sangre de alguno de sus hijos” (485), el joven Sandoval, que ha visto en el rostro del enemigo su propia humanidad, opta por despojarse de los atributos que constituyen su (im) postura heroica -sus armas, sus gestos, sus palabras- para delegar la posibilidad de luchar al otro social: el roto. Esta cesión revela la inestable posición de medianía que busca ocupar el protagonista de la novela entre las distintas capas sociales en tensión -fundamentalmente, entre futres y rotaje-, lo que en efecto parece expresar bien la función mediadora que el proyecto de Riquelme buscó cumplir entre un saber propio de las elites dominantes - la historia de las elites-y las aspiraciones de un heterogéneo segmento social, mesocrático y popular, al que apuntó con su texto. Sin embargo, es importante precisar que Riquelme no parece reconocer en las "masas populares" la posibilidad de constituirse en sujetos de clase capaces de generar transformaciones efectivas del orden político y social. Recordemos que el mismo autor condenó en su tiempo las políticas democratizadoras de Balmaceda, describiéndolas como una "fermentación política que [llevó] a la superficie social las materias que la ley de las densidades mantiene providencialmente en el fondo de la cuba" (1931 [1891]: 511). Opiniones como estas revelarían la concepción profundamente conservadora del liberalismo político y social de Riquelme, a pesar de que, consideradas en el enrarecido contexto político en que fueron formuladas, es posible que hayan estado fuertemente condicionadas por el temor real y efectivo a las represalias ${ }^{11}$.

${ }^{11}$ Como ya hemos indicado, pensamos que la orientación crítica que Riquelme imprime a su historia nacional se relaciona con la catástrofe histórica que significó la guerra civil de 1891, de la cual Riquelme participa como doble testigo, desde su rol como funcionario de la administración pública y como colaborador del periódico de oposición La Libertad Electoral, como veremos en la sección final de este artículo. Riquelme elabora de forma oblicua esta ambigua posición política en "Solo!" (1891), una interesante crónica escrita con ocasión del suicidio de Balmaceda, publicada en el $\mathrm{N}^{\circ} 25$ de la revista Anales de Literatura Chilena. 
En último término, lo que nos interesa destacar en esta lectura es el gesto a partir del cual el protagonista de Riquelme propone a sus lectores un renovado pacto con el porvenir: "desde hoi hasta el día de mi muerte, [lo] juro, que no privaré ni al chincol más infeliz de estas ramas, de este don de la vida, que no le he dado a nadie todavía" (1893: 94). Precisamente, es sobre este compromiso con la vida, la propia y la ajena, que el "héroe" de Riquelme puede imaginar un deseo erótico y político capaz de justificar el camino de la inacción: la "infinita satisfacción de estar vivo i de no haber privado a nadie de la misma felicidad" es suficiente para superar el atisbo de vergüenza que siente Sandoval al reencontrarse con Ema "sin herida alguna" (Riquelme, 1893: 182). Ahora bien, ¿qué sentido tiene la deserción del ideal heroico en el contexto que enmarca la producción y recepción de esta obra? ¿Cómo se articula esta postura con el resto de la producción de Riquelme? En el apartado final de este texto nos extenderemos sobre estos puntos.

\section{Consideraciones finales}

Sabemos que la tensión entre recuerdo y olvido constituyó una preocupación central en la obra de Riquelme, y que este interés por la memoria cambió de nivel, de la reminiscencia individual a la historia colectiva, coincidiendo con la catástrofe que significó la Guerra Civil de 1891 (Aguayo, 2014). Recordando los peores días del gobierno de Balmaceda, cuando la policía controlaba la vida santiaguina al ritmo del garrote y los purgantes, Riquelme concluye: "Olvidar es también una gran cosa, el secreto para ser feliz nada menos, salvo cuando los recuerdos pueden servirnos de espejo en el presente y de farol para lo venidero" (Riquelme, 1931 [1891]: 525). Puesto a recordar, por amistosa exigencia, la historia de una nación convaleciente de su ruina, el presente que se refleja oblicuamente en ese espejo lleno de fracturas estaba cargado con la sangre de los miles que murieron en las masacres de Concón y La Placilla, víctimas de una guerra fratricida ensalzada, sin embargo, por una elite ilustrada que, como ejemplifica el caso de Barros Arana, vio en esa tragedia la "victoria de nuestras augustas instituciones", un "triunfo brillante" comparable a las hazañas heroicas de la Independencia (1891: 2-3). Tal vez por eso, por las historias que ha leído 
pero también por la historia de la cual ha sido testigo y sobreviviente, a Riquelme le resultó imposible validar en su escritura el heroísmo de unas revoluciones políticas que reconoció históricamente programadas "por cuenta de los abogados" (Riquelme, 1894, mayo 4). De ahí que la lámpara de la historia que imagina prefiera iluminar figuras signadas por el acobardamiento y la falta de convicciones políticas, como ocurre con el ficticio "don Panchito" Sandoval -verdadero reverso de Rafal San Luis o Vicuña Mackenna- o con el histórico José Camilo Gallardo, uno de los olvidados padres del periodismo chileno, "hombre de paz, [que] nada valía fuera de su taller ni era para andanzas i quehaceres de guerrero" (1894, febrero 24). En esto residiría el aporte más original de Riquelme a la literatura del siglo que con él termina: en un héroe pacífico, medroso y hogareño que renuncia a la gloria épica y que opta no por "estar en el mundo y tener importancia dentro de él, sino [por] estar con el mundo, observarlo y vivirlo una y otra vez" (Bajtín 2003: 142).

Sloterdijk nos recuerda que, a diferencia del héroe, el cobarde privilegia la huida antes que la confrontación, opción que le permite, por lo general, sobrevivir cuando todos los demás han muerto. El precio que paga por su transgresión, en una cultura dominada por el ideal heroico, es el señalamiento. No cae sobre su nombre el olvido pasivo que desvanece el recuerdo de los vacilantes, sino que pesa sobre él una condena activa y colectiva. De ahí que, a diferencia de la claridad solar del héroe, que se expone abierta y casi alegremente a la muerte, el cobarde deba actuar a la sombra de sus artimañas, en una lucha que continúa después de que terminan las batallas: tiene que sobrevivir a los recuerdos y al olvido, volverse irreconocible, desarmarse, fingir, "ocultar que realmente es el antihéroe, [...] enmascararse y por todos los medios hacerse imperceptible” (Sloterdijk, 2003: 334). Sugerentemente, ese camino lo conduce a (re)conocer lo que se disimula tras la máscara del heroísmo, lo que se oculta tras su justicia, su honor o su valentía. Pensamos que esa clase de (re)conocimiento parece guiar el desarrollo de la prosa histórica que buscó popularizar Riquelme hasta el final de sus días. Los sarcásticos detalles con que caracteriza momentos claves en la historia de las instituciones nacionales, desde el "primer fraude electoral que vio Santiago" y que dio a Pedro de Valdivia el poder para independizarse de Pizarro (Riquelme 1908, septiembre 11); pasando por la Constitución de 1812, "aprobada por el pueblo en una farsa mui ofi- 
cial” (Riquelme 1894, febrero 24); por el plebiscito arreglado por O’Higgins para declarar la Independencia - "porque no será a Chile, envejecido en elecciones, a quien cuatro gatos o los que los pelan, le ganen una elección” (Riquelme 1909, febrero 16)-, y terminando con las acciones del Congreso de su propia época, que surge victorioso de la crisis de 1891 pero que "hace y viola, como San Bruno, las leyes de la nación” (Riquelme 1909, abril 19), advierten a sus lectores de las grietas imperceptibles que minan la legitimidad del proyecto nacional desde su fundación hasta su mismo presente, develando la falsedad y las ambiciones homicidas que se ocultan tras el brillo épico de la historia.

Finalmente, y a manera de síntesis, podemos afirmar que la prosa histórica de Riquelme, a pesar de las limitaciones estilísticas y las ambigüedades ideológicas que sus comentaristas han sabido notar, fue el resultado de un proyecto conscientemente crítico y creativo que no se agotó en la difusión de una historia nacional simplificada para ilustrar al emergente público mesocrático y popular. Al contrario, nos parece que, vistos como conjunto, los artículos de Riquelme develan una atenta percepción del devenir histórico de la comunidad nacional, interpretándolo desde una perspectiva esencialmente cuestionadora y contingente, y adoptando para ello formas que dialogaron tanto con las convenciones de la cultura dominante como con expresiones propias de una cultura popular en expansión. De esta forma, pensamos que es posible reconocer en esta "popularización" de la memoria nacional un capítulo más en la historia de las mediaciones textuales que apuntaron a satisfacer las necesidades y los deseos de un público heterogéneo, compuesto por los emergentes sectores medios y populares que ocuparon un lugar cada vez más relevante en el mercado lector de fines del siglo XIX y principios del siglo XX.

\section{Referencias}

Aguayo, E. (2014). Entre historia y ficción: la retórica de la memoria en la prosa de Daniel Riquelme (1893-1911). Co-herencia, 21, 49-68.

Amunátegui, D. (1915). Bosquejo histórico de la Literatura Chilena. Santiago de Chile: Imprenta Universitaria.

Baradit, J. (2015). Historia secreta de Chile. Santiago: Penguin Random House Grupo Editorial S.A. 
Bajtín, M. (2003). Estética de la creación verbal. 11 ${ }^{\mathrm{a}}$ edición. México, D.F.: Siglo XXI Editores.

Barros Arana, D. (1887). Historia Jeneral de Chile. Tomo VIII. Santiago: Rafael Jover, Editor.

. (1891). Historia Jeneral de Chile. Tomo XI. Santiago: Rafael Jover, Editor.

Blest Gana, A. (2013). Martín Rivas. Santiago de Chile: Origo Ediciones.

Concha, J. (2012). Leer a contraluz. Estudios sobre narrativa chilena. De Blest Gana a Varas y Bolaño. Santiago de Chile: Ediciones Universidad Alberto Hurtado.

Erll, A. (2008). Culture Memory Studies: An Introduction. En A. Erll y A. Nünning (eds.), Cultural Memory Studies. An international and interdisciplinary handbook (pp. 1-18). Berlín: Walter de Gruyter.

Falleto, E. y Kirkwood, J. (1976). Sociedad burguesa y liberalismo romántico en el siglo XIX. Chile: FLACSO.

Gazmuri, C. (2006). La historiografía chilena (1842-1970). Tomo I (18421920). Santiago de Chile: Aguilar Chilena de Ediciones S.A.

García, A. (2011). Noticia introductoria. En M. López (comp.), Escritos republicanos: selección de escritos políticos del siglo XIX (pp. 157-169). Santiago de Chile: Lom Ediciones.

Latorre, M. y Varas, M. (eds). (1931). Cuentos de la guerra y otras páginas de Daniel Riquelme (pp. 483-507). Santiago de Chile: Imprenta Universitaria.

Menton, S. (1993). Latin America's new historical novel. Austin, TX: University of Texas Press.

Mínguez, V. (2003). Héroes clásicos y reyes héroes en el antiguo régimen. En M. Chust y V. Mínguez (eds.), La construcción del héroe en España y México (1789-1847) (pp. 51-70). Valencia: Publicacions de la Universitat de València.

Ossandón, C., Santa Cruz, E. (2001). Entre las Alas y el Plomo. La gestación de la prensa moderna en Chile. Santiago de Chile: Lom Ediciones.

Palma, M. (1870). Los secretos del pueblo. Novela social y de costumbres. Tomo IV. Valparaíso: Imprenta del Mercurio.

Poblete. J. (2003). Literatura chilena del siglo XIX: entre públicos lectores y figuras autoriales. Santiago de Chile: Editorial Cuarto Propio.

Riquelme, D. (1888, septiembre 17). Pequeñeces. La Libertad Electoral. . (2016 [1891, septiembre 21]). Solo! En E. Aguayo y A. Rey. "Solo!" (1891), de Daniel Riquelme: Testimonio imaginario de una crisis histórica. Anales de Literatura Chilena, 25, 213-219.

. (1893). Episodios chilenos. La revolución del 20 de abril de 1851. Santiago de Chile: Imprenta de La Libertad Electoral. . (1894, febrero 24). La Aurora de Chile. La Libertad Electoral. 
. (1894, mayo 4). Episodios chilenos. La de Pan Francés. La Libertad Electoral.

. (1894, mayo 31). Episodios chilenos. El terremoto del señor de mayo. La Libertad Electoral.

. (1898, abril 14). La guardia nacional en 1806 i 7. La Libertad Electoral. . (1898, junio 23). Crónicas santiaguinas. La avenida grande. La Libertad Electoral.

. (1898, diciembre 14). La batalla de Loncomilla. El Mercurio de Valparaíso.

. (1899, abril 5). La semana santa de 1818. La Libertad Electoral.

. (1905). El terremoto del Señor de Mayo. Santiago de Chile: Imprenta Cervantes.

. (1908, septiembre 11). Destrucción de Santiago en 1541. Pedro de Valdivia. El Mercurio.

. (1909, enero 31). Yungay y Pan de Azúcar. El Mercurio.

. (1909, febrero 16). Recuerdos de un viejo. La jura de la Independencia.

El Mercurio.

. (1909, abril 19). Dramas de la plaza de armas. El fusilamiento de San

Bruno. El Mercurio.

. (1909, agosto). El choclo de Chile. Selecta.

. (1909, diciembre 20). Revoluciones nacionales. Barrabás. El Mercurio.

. (1910, enero 23). Episodios de la Marina Chilena. La Lautaro y la Esme-

ralda. El Mercurio.

. (1931 [1891]). En tiempo de los pacos. En M. Latorre y M. Varas (eds.), Cuentos de la guerra y otras páginas de Daniel Riquelme (pp. 508-532). Santiago de Chile: Imprenta Universitaria.

. (1931 [1909]). La revolución de los sastres de Valparaíso. En M. Latorre y M. Varas (eds), Cuentos de la guerra y otras páginas de Daniel Riquelme (pp. 483-507). Santiago de Chile: Imprenta Universitaria.

. (1932 [1894]). Muerte de portales. Páginas de sangre de la historia de Chile. Santiago: Biblioteca Vida Chilena.

Salazar, G., Pinto, J. (1999). Historia contemporánea de Chile: Actores, identidad y movimiento. Santiago de Chile: Lom Ediciones.

Salinas, M. (1998). En el chileno el humor vive con uno: el lenguaje festivo y el sentido del humor en la cultura oral popular de Chile. Santiago de Chile: Lom Ediciones.

Sarlo, B. (2013). Tiempo pasado. Cultura de la memoria y giro subjetivo. Una discusión. Talca: Editorial Universidad de Talca.

Sloterdijk, P. (2003). Crítica de la razón cínica. Madrid: Ediciones Siruela S.A.

Sommer, D. (2004). Ficciones fundacionales: Las novelas nacionales de América Latina. Bogotá: Ediciones Fondo de Cultura Económica. 
Subercaseaux, B. (2002). Nación y cultura en América Latina: diversidad cultural y globalización. Santiago de Chile: Lom Ediciones. . (2011). Historia de las ideas y de la cultura en Chile. Desde la Independencia hasta el Bicentenario. Volumen I. Santiago de Chile: Editorial Universitaria S.A.

Todorov, T. (2002). Memoria del mal, tentación del bien. Indagación sobre el siglo XX. Barcelona: Ediciones Península.

Unzueta, F. (1997). Género y sujetos nacionales: en torno a las novelas históricas de Lindaura Anzoátegui. Revista Iberoamericana, 178-179, 219-229.

Vicuña Mackenna, B. (1862). Historia de los diez años de la administración de don Manuel Montt. Levantamiento i sitio de la serena. Santiago de Chile: Imprenta Chilena.

. (1878). Historia de la jornada del 20 de abril de 1851. Una batalla en las calles de Santiago. Santiago de Chile: Rafael Jover Editor.

Vicuña, M. (2009). Un juez en los infiernos. Benjamín Vicuña Mackenna. Santiago de Chile: Ediciones Universidad Diego Portales.

Vovelle, M. (2003). La revolución francesa: ¿Matriz de la heroización moderna? En M. Chust y V. Mínguez (eds.), La construcción del héroe en España y México (1789-1847) (pp. 19-29). Valencia: Publicacions de la Universitat de València.

Williams, R. (2005). Base and superstructure in Marxist Cultural Theory. En Culture and materialism (pp. 31-49). London: Verso. 